\title{
Immune Reconstitution Therapy or Continuous Immunosuppression for the Management of Active Relapsing-Remitting Multiple Sclerosis Patients? A Narrative Review
}

\author{
Isa Ahmed AlSharoqi $\cdot$ Mohamed Aljumah $\cdot$ Saeed Bohlega $\cdot$ Cavit Boz $\cdot$ Abdelkader Daif $\cdot$ \\ Salam El-Koussa $\cdot$ Jihad Inshasi $\cdot$ Murat Kurtuncu $\cdot$ Thomas Müller $\cdot$ Chris Retief \\ Mohammad Ali Sahraian • Vahid Shaygannejad · Ilham Slassi · Karim Taha · Magd Zakaria • \\ Per Soelberg Sørensen
}

Received: March 17, 2020/ Published online: April 15, 2020

(C) The Author(s) 2020

\section{ABSTRACT}

The majority of disease-modifying drugs (DMDs) available for the management of active relapsing-remitting multiple sclerosis (RMS) depend on continuous drug intake for maintained efficacy, with escalation to a more active

Digital Features To view digital features for this article go to https://doi.org/10.6084/m9.figshare.12046425.

I. A. AlSharoqi $(\bowtie)$

Department of Clinical Neurosciences, Salmaniya

Medical Complex, PO Box 12, Manama, Bahrain

e-mail: isasharoqi2@hotmail.com

M. Aljumah

King Fahad Medical City, Ministry of Health,

Riyadh, Kingdom of Saudi Arabia

\section{S. Bohlega}

Department of Neurosciences, King Faisal Specialist Hospital and Research Centre, Riyadh, Kingdom of Saudi Arabia

C. Boz

Department of Neurology, Karadeniz Technical University, Trabzon, Turkey

A. Daif

King Khalid University Hospital, King Saud

University, Riyadh, Kingdom of Saudi Arabia

S. El-Koussa

Hopital Libanais Geitaoui, Beirut, Lebanon drug when an unacceptable level of disease activity returns. Among continuously applied regimens, interferons and glatiramer acetate act as immunomodulators, while dimethyl fumarate, fingolimod, ocrelizumab, natalizumab and teriflunomide are associated with continuous immunosuppression. By contrast, immune reconstitution therapy (IRT) provides efficacy that outlasts a short course of treatment. Autologous hemopoietic stem cell transplantation is perhaps the classic example of IRT, but

\section{J. Inshasi}

Neurology Department, Rashid Hospital and Dubai Medical College, Dubai Health Authority, Dubai, United Arab Emirates

\section{Kurtuncu}

Department of Neurology, Istanbul Faculty of Medicine, Istanbul University, Istanbul, Turkey

\section{T. Müller}

Department of Neurology, St. Joseph Hospital

Berlin-Weissensee, Gartenstr. 1, 13088 Berlin, Germany

\section{Retief}

Life Wilgers Hospital, Pretoria, South Africa

\section{A. Sahraian}

MS Research Center, Neuroscience Institute, Tehran University of Medical Sciences, Tehran, Iran 
this invasive and intensive therapy has challenging side-effects. A short treatment course of a pharmacologic agent hypothesized to act as an IRT, such as Cladribine Tablets $3.5 \mathrm{mg} / \mathrm{kg}$ or alemtuzumab, can provide long-term suppression of MS disease activity, without need for continuous treatment (the anti-CD20 mechanism of ocrelizumab has the potential to act as an IRT, but is administered continuously, at 6-monthly intervals). Cladribine Tablets $3.5 \mathrm{mg} / \mathrm{kg}$ shows some selectivity in targeting adaptive immunity with a lesser effect on innate immunity. The introduction of IRT-like diseasemodifying drugs (DMDs) challenges the traditional maintenance/escalation mode of treatment and raises new questions about how disease activity is measured. In this review, we consider a modern classification of DMDs for MS and its implications for the care of patients in the IRT era.

Keywords: Disease-modifying drug; Escalation therapy; Immune reconstitution therapy; Maintenance therapy; Multiple sclerosis

V. Shaygannejad

Isfahan Neurosciences Research Center, Alzahra Research Institute, Isfahan University of Medical Sciences, Isfahan, Iran

I. Slassi

Department of Neurology, Sheikh Khalifa Ibn Zaid Hospital, Mohammed VI University, Casablanca, Morocco

K. Taha

Merck, Dubai, United Arab Emirates

M. Zakaria

Faculty of Medicine, Ain Shams University, Cairo, Egypt

P. S. Sørensen

Danish Multiple Sclerosis Center, University of Copenhagen-Rigshospitalet, Copenhagen,

Denmark

\section{Key Summary Points}

The majority of disease-modifying drugs (DMDs) available for the management of multiple sclerosis (MS) depend on continuous drug intake for maintained efficacy, with escalation to a more active drug when an unacceptable level of disease activity returns.

Immune reconstitution therapy (IRT) provides efficacy that outlasts a short course of treatment.

Pharmacological IRT, currently Cladribine Tablets $3.5 \mathrm{mg} / \mathrm{kg}$ or alemtuzumab, can provide long-term suppression of MS disease activity, without need for continuous treatment.

Cladribine Tablets $3.5 \mathrm{mg} / \mathrm{kg}$ shows some selectivity in targeting adaptive immunity with a lesser effect on innate immunity.

The introduction of IRT-like diseasemodifying drugs challenges the traditional maintenance/escalation mode of treatment and raises new questions about how disease activity is measured.

\section{INTRODUCTION}

The management of active relapsing-remitting multiple sclerosis (RMS) has been based traditionally on maintenance therapy in which the patient takes a given disease-modifying drug (DMD) continuously, with a return of relapses when the drug is discontinued [1]. This approach has brought success: more than two decades of therapeutic use of beta-interferons, for example, has reduced relapse rates and disease worsening across the MS population as a whole [2]. A DMD with higher efficacy may be needed in the event of breakthrough relapse(s), worsening of disability (escalation) or where MS is highly active at diagnosis. In the last decade, we have witnessed an impressive increase in the 
availability of new DMDs for the management of RMS that are taking us beyond the age of maintenance/escalation therapy. Many of these are high-efficacy drugs, but their use is also accompanied by significant safety concerns and/or monitoring schemes that may be burdensome [3]. DMDs that act in the manner of an immune reconstitution therapy (IRT) have the potential to protect against relapses for years after a short course of treatment. In this review, we compare the therapeutic profiles of DMDs hypothesized to act like an IRT and the classical application of maintenance/escalation therapy in terms of their associated treatment burdens, MS outcomes and safety. This article is based on previously conducted studies and does not contain any studies with human participants or animals performed by any of the authors.

\section{CLASSIFICATION OF MS THERAPIES}

\section{Immunomodulation Versus Immunosuppression}

Maintenance treatment for RMS includes immunosuppressants and immunomodulators (Table 1). Reduced efficacy or activity of the immune system, which is associated with significant lymphopenia during immunosuppression, may diminish immune responses to infectious agents or to vaccinations. In comparison, immunomodulators do not impair the overall activity of the immune system; rather, they interact in multiple ways with components of the immune system that are still incompletely understood. For example, interferonbeta inhibits the activation and proliferation of lymphocytes and the entry of lymphocytes into the central nervous system (CNS) [4]. This results in a shift in the balance of cytokine production from pro- to anti-inflammatory [4]. Glatiramer acetate, another immunomodulator, also reduces the net production of inflammatory cytokines via different mechanisms, including within the CNS [4].

The World Health Organization Collaborating Center for Drug Statistics has provided a classification of drugs that sheds some light on their mechanisms of action (also included in Table 1) [5]. Most current maintenance therapies involve continuous administration (although maintenance treatment with ocrelizumab involves infusions at 6-monthly intervals). Some current maintenance therapies for RMS target lymphocytes to cause profound and continuous suppression of peripheral lymphocytes (e.g. fingolimod [6], dimethyl fumarate [7]), of lymphocytes within the CNS (natalizumab [8]) or of CD19+ lymphocytes (ocrelizumab [9]). Teriflunomide inhibits the response of the immune system to a stimulus [10], while the mechanism of action of dimethyl fumarate on immune function is complex [11]. Cladribine Tablets $3.5 \mathrm{mg} / \mathrm{kg}$ (refers in this article to Cladribine Tablets $10 \mathrm{mg}$, given to achieve $3.5 \mathrm{mg} / \mathrm{kg}$ cumulative dose over 2 years) and alemtuzumab act in different ways to the other DMDs in that list (see Fig. 1), as will be described in the following text.

Continuous immunosuppression has important functional consequences for the therapeutic use of these drugs, as this treatment has been associated with an increased risk of infections $[12,13]$ and, in some cases, increased risk of malignancy $[14,15]$. The implications of these observations for individual DMDs, including those that act like IRTs, is described in the following sections.

\section{Immune Reconstitution Therapy}

\section{Autologous Hematopoietic Stem Cell Transplantation}

The key characteristic of an IRT is a long-lasting period of efficacy (however measured, see below) that follows an initial short course of treatment, without continued exposure to the drug. Autologous hematopoietic stem cell transplantation (aHSCT) provides a useful working definition of an IRT [16].

Briefly, in aHSCT HCSs are mobilized from the bone marrow and harvested, following which the patient's pathological immune system is ablated entirely using strong immunosuppressive drugs; subsequent reinfusion of the HSCs allows the immune system to rebuild, without further autoimmunity if the treatment 
is successful $[16,17]$. Clinical studies suggest that aHSCT is an effective treatment, with progression-free survival in $70-91 \%$ of patients, MRI event-free survival in $85-100 \%$ and "no evidence of disease activity" (NEDA) in 68-70\%, at 4-5 years post-treatment [16]. The toxicity of aHSCT includes a low but measureable risk of treatment-related mortality, the possibility of prolonged hospitalization, viral reactivation and secondary autoimmunity and a probable impact on fertility [16]. Therefore, aHSCT is unsuitable for wide use.

The effects of aHSCT on immune cell populations appear to be more profound than those with any pharmacologic DMD [18]. However, DMDs with the characteristics of an IRT may present a more practicable alternative for most patients requiring high-efficacy therapy for MS [19-21]. Key therapeutic properties of these DMDs are summarized below.

\section{Alemtuzumab}

Alemtuzumab is administered over treatment periods consisting of five daily infusions followed by three daily infusions 1 year later [22]. One or two additional 3-day courses are supported if clinical MS events or MS events based on imaging criteria occur, with a minimum of 1 year between courses. Treatment with alemtuzumab rapidly and selectively removes about $95 \%$ of circulating lymphocytes [23]. The authors of a systematic review suggested that alemtuzumab reduces CD4+ and CD8+ T cells to a greater extent than does Cladribine Tablets, with a similar effect on B cells [18]. The molecular target of alemtuzumab, CD52 antigen, is also present on components of the innate immune system, including monocytes and dendritic cells, which are reduced in number following treatment with alemtuzumab [24-26]. The levels of these cells may recover over a period of about 6 months. Severe neutropenia is rare during treatment with alemtuzumab, however, and the extent of depletion of neutrophils is mild in most patients [27]. The nadir of lymphocyte count occurs at 1 month post-treatment; B cells recover over a period of about 3 months (and markedly overshoot the pretreatment value), while repopulation of $\mathrm{T}$ cells takes at least 1 year $[23,24]$. In one study,
CD4 and CD8 counts were $30-40 \%$ of pretreatment values at 18 months after treatment [28].

The clinical benefits of alemtuzumab (reduced MS relapses and reduced disability) have been observed for up to a 5-year period of follow-up, without further DMD treatment $[23,28]$. Accordingly, alemtuzumab acts like an IRT, with some effect on both the innate and adaptive immune systems (see Fig. 1). Indeed, an action on the innate immune system has been described as an important contributor to the efficacy of alemtuzumab [28]. Improved efficacy without additional safety concerns has been found with continuance of the second course of alemtuzumab when relapses occurred after the first course [29] and administration of additional courses of alemtuzumab when RMS disease activity continued after the second course [30].

Treatment with alemtuzumab is associated with an increased risk of bacterial infections (including listeriosis and tuberculosis [TB]), viral infections (herpes simplex and zoster and human papillomavirus) and fungal infections $[31,32]$. The increased incidence of bacterial and fungal infections may be consistent with the drug's suppression of innate and adaptive immunity [33]. A high incidence of secondary autoimmunity, especially in the thyroid (where Graves' hyperthyroidism and Hashomoto thyroiditis account for about three-quarters of cases of thyroid dysfunction [34]) and platelets (which can cause immune thrombocytopenia), is believed to be associated with reconstitution of the lymphocytes [32, 35]. To date, there has been no clear signal for a general increase in the risk of malignancy with alemtuzumab, compared with other DMDs. The European labeling for the drug cites a risk of thyroid cancer associated with secondary autoimmunity [22], but it is unclear to what extent this was based on observation bias arising from increased monitoring of the thyroids of alemtuzumab-treated patients [36]. The US label for alemtuzumab identifies an elevated risk of lymphoproliferative disorders, lymphomas and malignant melanoma [37]. The long-term safety profile of alemtuzumab in a global safety database is consistent with the known tolerability and safety profiles of this agent [38]. At the time of 
writing, the use of alemtuzumab has been restricted due to safety concerns, including severe neutropaenia, immune-mediated reactions and adverse events in the cardiovascular system (such as pulmonary bleeding, stroke, myocardial infarction, cervicocephalic arterial dissection $[39,40])$.

\section{Cladribine Tablets $3.5 \mathrm{mg} / \mathrm{kg}$}

Cladribine Tablets $3.5 \mathrm{mg} / \mathrm{kg}$ is a relatively newly introduced management option for MS. Four sessions of treatment are required in total: two periods of 5 consecutive days of treatment are given 1 month apart at the initiation of treatment, which is repeated after 1 year [41]. The labeling also states that there is "no requirement" for further treatment for years 3 and 4 .

A profound and almost complete reduction in B cells (CD19+) is observed within weeks of administration of Cladribine Tablets $3.5 \mathrm{mg} / \mathrm{kg}$; recovery to the normal range is usually achieved at around 12 months post-treatment [42-44]. A more gradual, but incomplete, reduction, in CD4+ and CD8+ T cells occurs; CD4+ cells recover to the normal range in about 18 months, while CD8+ cells do not fall below the normal range. Mild-to-moderate reductions in neutrophil counts have been observed in about $25 \%$ of patients according to the US Prescribing Information [45]. Importantly, other cell types, including monocytes, are little affected by Cladribine Tablets $3.5 \mathrm{mg} / \mathrm{kg}$, indicating a relatively minor effect on the innate immune system.

Clinical trials have demonstrated the efficacy of Cladribine Tablets $3.5 \mathrm{mg} / \mathrm{kg}$ over 2 years of follow-up in patients with RMS, including reductions in relapse rates, magnetic resonance imaging (MRI)-based disease activity and progression of disability [46-48]. Longer-term efficacy was observed in an extension to a clinical trial in RMS patients that involved a total of 4 years of follow-up $[49,50]$. Importantly, in this extension study, relapse rates were similar for patients who continued to receive Cladribine Tablets $3.5 \mathrm{mg} / \mathrm{kg}$ and those who were re-randomized to placebo [49]. Overall, the short course of treatment and extended period of efficacy beyond the period of reduction in lymphocyte counts observed in many patients is consistent with an IRT-like mechanism (Fig. 1) [17]. Treatment with Cladribine Tablets $3.5 \mathrm{mg} / \mathrm{kg}$ also reduced the rate of conversion to clinically definite MS over 2 years in patients with a first demyelinating event [51].

Treatment with Cladribine Tablets $3.5 \mathrm{mg} / \mathrm{kg}$ may be associated with reactivation of herpes zoster or TB, in particular in patients with profound lymphopenia (grade 3 or 4 ), as described in its labeling [41]. There has also been a recent case report of lichenoid rash associated with Cladribine Tablets in a single patient, which resolved with appropriate management [52].

The prescribing information describes a numerical increase in the risk of malignancy. A meta-analysis of 11 clinical trials performed with various DMDs demonstrated an unexpected absence of malignancy in the placebo group of the principal Phase 3 study of Cladribine Tablets, and this was significantly lower than that in the placebo groups of the trials of other DMDs. Moreover, in this metaanalysis, the incidence of malignancy was not higher for Cladribine Tablets $3.5 \mathrm{mg} / \mathrm{kg}$ compared to the other DMDs [53]. Epidemiological analyses based on the GLOBOCAN reference database support those findings, since they showed that Cladribine Tablets-treated subjects did not show an excess of malignancies compared with the general population, with a standardized incidence ratio for any cancer of 0.97 (95\% confidence interval [CI] 0.44-1.85) for Cladribine Tablets $3.5 \mathrm{mg} / \mathrm{kg}$ and 0.48 (95\% CI 0.14-1.53) for placebo [54]. An integrated analysis of clinical evaluations of Cladribine Tablets $3.5 \mathrm{mg} / \mathrm{kg}$ that included all patients who received this treatment revealed an excess risk of 0.20 events $/ 100$ patient-years (95\% CI -0.0785 to 0.3947 ) versus placebo, which was not statistically significant [55].

\section{Ocrelizumab}

The anti-CD20 mechanism of ocrelizumab has the potential to act like an immune reconstitution therapy, and ocrelizumab has been described in these terms [56]. However, this agent is given continuously, albeit with a long dosing interval of 6 months during maintenance treatment [57], consistent with the manner of its administration in its pivotal 


\begin{tabular}{|c|c|c|c|}
\hline \multicolumn{2}{|c|}{$\begin{array}{c}\text { Maintenance/escalation } \\
\text { therapy }\end{array}$} & \multicolumn{2}{|c|}{$\begin{array}{l}\text { Immune reconstitution } \\
\text { therapy-like action }\end{array}$} \\
\hline $\begin{array}{l}\text { Immunostimulation/ } \\
\text { immunomodulation }\end{array}$ & $\begin{array}{c}\text { Continuous } \\
\text { immunosuppression }\end{array}$ & More selective ${ }^{a}$ & Less selective ${ }^{a}$ \\
\hline Interferons & Dimethyl fumarate & Cladribine & Alemtuzumab \\
\hline \multirow[t]{4}{*}{ Glatiramer acetate } & Fingolimod & & \\
\hline & Ocrelizumab & & \\
\hline & Natalizumab & & \\
\hline & Teriflunomide & & \\
\hline
\end{tabular}

Fig. 1 Modern classification of disease-modifying drugs used in the management of active relapsing-remitting multiple sclerosis, with reference to the mechanism of

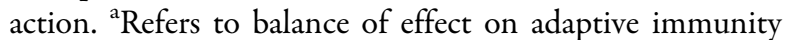
and innate immunity, with "more selective" implying a greater effect on the former and a lesser effect on the latter.

clinical trials in persons with MS [9]. Ocrelizumab is effective in RMS, achieving reductions of $46-47 \%$ in relapse rates and reduced rates of disability progression, compared with interferon-beta [9]. However, it is not known whether the efficacy of ocrelizumab outlasts the period of its administration in the manner of other treatments hypothesized to act like an IRT [19]. Reviews in this area have described ocrelizumab as an agent which "might be either called a chronic immunosuppressive or pulsed immune reconstitution therapy" [19] or have placed this agent in a class of its own between maintenance therapy and IRT [20].

\section{IMPLICATIONS FOR PATIENTS}

\section{Clinical Efficacy and Safety}

The data summarized so far in this review show that available DMDs hypothesized to act like IRTs for RMS demonstrate durable efficacy. Although it is not possible to exclude an increased risk of malignancy with IRT-like DMDs at the present time, the data summarized above on malignancy rates for IRT-like drugs do not suggest a strong signal for increased risk of malignancy. There is clearly a need for further data on the potential of IRT-like DMDs for
Autologous hemopoiteic stem cell transfusion is not included here, but would be considered to be a nonselective immune reconstitution therapy, as it involves ablation of the patient's entire immune system (see text for details)

increasing the risk of malignancy, especially data on the newer agents. Such data take time to collect, and short-term trials are not designed or powered to assess this outcome. Ongoing registries can play an important role in defining the true long-term risk:benefit profiles of all DMDs, including alemtuzumab and Cladribine Tablets $3.5 \mathrm{mg} / \mathrm{kg}$.

\section{Burden of Treatment}

A short course administration of a DMD is more convenient for patients than continuous treatment [21]. The use of IRT-like DMDs also effectively bypasses issues of adherence to therapy, which is known to influence outcomes in RMS [58]. Pretreatment with a corticosteroid is recommended for ocrelizumab [57] and alemtuzumab [22]. Additional pretreatment with an antihistamine is required for ocrelizumab, and an antipyretic recommended for both ocrelizumab and alemtuzumab [22, 57]. No pretreatment is required for Cladribine Tablets $3.5 \mathrm{mg} / \mathrm{kg}$ [41].

Monitoring burdens also vary greatly between treatments. Focusing on alemtuzumab, thyroid tests are required at 3-monthly intervals, and full differential blood counts, serum creatinine and microscopic urinalysis should be 
Table 1 Brief overview of the action of disease-modifying therapies on the immune system

\begin{tabular}{|c|c|c|}
\hline $\begin{array}{l}\text { Disease- } \\
\text { modifying } \\
\text { therapies }\end{array}$ & $\begin{array}{l}\text { World Health } \\
\text { Organization } \\
\text { classification }\end{array}$ & Effect on the immune system \\
\hline Interferon-beta & Immunomodulating agent & Does not cause profound or continuous suppression of immune function \\
\hline Glatiramer acetate & Immunostimulator & \\
\hline $\begin{array}{l}\text { Dimethyl } \\
\text { fumarate }\end{array}$ & $\begin{array}{l}\text { Other } \\
\text { immunosuppressants }\end{array}$ & $\begin{array}{l}\text { Complex mechanism involving decreased B-cell CD40 expression that is } \\
\text { associated with disrupted B-cell activation, decreases in memory T-cells } \\
\text { and T-cell proliferation and activation [7]. Causes lymphopenia }\end{array}$ \\
\hline Teriflunomide & $\begin{array}{l}\text { Selective } \\
\text { immunosuppressant }\end{array}$ & $\begin{array}{l}\text { Inhibits the expansion of lymphocyte numbers in response to a stimulus } \\
{[10]}\end{array}$ \\
\hline Fingolimod & $\begin{array}{l}\text { Selective } \\
\text { immunosuppressant }\end{array}$ & Continuous suppression of peripheral lymphocytes [6] \\
\hline Natalizumab & $\begin{array}{l}\text { Selective } \\
\text { immunosuppressant }\end{array}$ & $\begin{array}{l}\text { Acts as a compartmentalized immunosuppressant in the central nervous } \\
\text { system only [8] }\end{array}$ \\
\hline Ocrelizumab & $\begin{array}{l}\text { Selective } \\
\text { immunosuppressant }\end{array}$ & Inhibition of CD20 lymphocytes [9] \\
\hline Alemtuzumab & $\begin{array}{l}\text { Selective } \\
\text { immunosuppressant }\end{array}$ & Actions consistent with a mechanism involving immune reconstitution ${ }^{\mathrm{a}}$ \\
\hline $\begin{array}{l}\text { Cladribine } \\
\text { Tablets }\end{array}$ & $\begin{array}{l}\text { Selective } \\
\text { immunosuppressant }\end{array}$ & \\
\hline
\end{tabular}

a See text for references

conducted monthly (in addition to measurements of each of these parameters before starting treatment) and continued for 4 years after the last treatment, according to European labeling [22]. The corresponding monitoring burden for Cladribine Tablets $3.5 \mathrm{mg} / \mathrm{kg}$ is lower. Blood counts must be performed before each treatment course in years 1 and 2 (with treatment given if values are $\geq 1000 / \mathrm{mm}^{3}$ and $800 / \mathrm{mm}^{3}$, respectively), and again 2 and 6 months after each treatment course (with additional monitoring needed only if blood counts are below these values) [41].

\section{What We Don't Know-Issues for the Future}

\section{What to Measure?}

With the increasing efficacy of treatments for RMS, attention is shifting from the use of relapse rates as a marker of efficacy towards the use of NEDA as a treatment outcome [59-61]. NEDA is linked to both improved short-term patient outcomes and also to the prevention of long-term disability in MS. Ongoing research will define which of several versions of NEDA to use. NEDA-3 requires the observation of no new MRI-based events plus no disability progression, and NEDA- 4 adds a measure of brain atrophy [60, 61]. "Minimal evidence of disease activity" (MEDA) has also been proposed as a treatment outcome in order to allow for a low level of MRI activity [61].

Substantial proportions of patients with RMS in analyses from recent trials have achieved NEDA for up to 2 years, including those in trials evaluating Cladribine Tablets $3.5 \mathrm{mg} / \mathrm{kg}$ (44 vs. $16 \%$ on placebo over 96 weeks in the CLARITY study $[46,62]$ ), ocrelizumab (48 vs. $25-29 \%$ on interferon-beta-1a in the OPERA I and II trials $[9,63])$ and alemtuzumab (39 vs. $27 \%$ and 32 vs. 
$14 \%$, each compared with interferon-beta-a in the CARE MS I and CARE MS II trials, respectively $[64,65])$. Other high-efficacy DMDs have also demonstrated high achievement of NEDA, such as natalizumab (37 vs. $7 \%$ on placebo in the AFFIRM study $[66,67]$ ), fingolimod (33 vs. $13 \%$ on placebo in the FREEDOMS study $[68,69])$, dimethyl fumarate (28 vs. $15 \%$ on placebo in the DEFINE study [70, 71]) and teriflunomide (23\% in the TEMSO study $[72,73])$. Accordingly, the use of NEDA as an outcome may influence the application of therapy in the IRT era. It has been suggested that while a relapse on maintenance/escalation therapy would lead to a switch to a higher-activity $\mathrm{DMD}$, the re-emergence of disease activity in a patient receiving an IRT-like DMD may lead to further application of the same treatment before a switch [62].

\section{Who to Treat with an IRT-like DMD?}

The prospect of long-term remission of RMS with DMDs that resemble IRTs challenges the traditional escalation/maintenance treatment pathway of starting patients on a classical firstline agent and switching them to more active therapies only with relapse. A recent benefit:risk assessment of Cladribine tablets for patients with RMS, compared with other DMDs using a multi-criteria decision analysis model, confirmed the applicability of Cladribine Tablets for use in patients with RMS, especially for those with high disease activity [74]. The IRT approach provides an additional management option, especially for patients presenting with highly active disease: such patients now have the option of a trade-off between an increased risk of side-effects with a highly active therapy, such as an IRT, and the potential of greater long-term efficacy. The low treatment and monitoring burden of Cladribine Tablets $3.5 \mathrm{mg} / \mathrm{kg}$ may be an important factor in the choice of therapy for such patients.

\section{CONCLUSIONS}

The availability of DMDs that appear to act like an IRT is a major advance in the management of RMS. Many patients achieve long-term remission of disease activity for several years, with a reduced treatment burden and without the potential of long-term continuous immunosuppression to promote malignancy. In addition, the short-course nature of DMDs that act like an IRT broadens the options for applying highly active therapy for RMS and facilitates individualization of therapy in accordance with individual patient preferences. Longer-term follow-up with any new agents is needed to better define their benefit:risk profile.

\section{ACKNOWLEDGEMENTS}

This article arose from a meeting organized by Merck Serono Middle East FZ-LLC, an affiliate of Merck KGaA, Darmstadt, Germany.

Funding. Merck Serono Middle East FZ-LLC funded the Rapid Service Fee and funded the study.

Medical Writing and/or Editorial Assistance. A medical writer (Dr Mike Gwilt, GT Communications, funded by Merck Serono Middle East FZ-LLC) provided editorial assistance.

Authorship. All named authors meet the International Committee of Medical Journal Editors (ICMJE) criteria for authorship for this article, take responsibility for the integrity of the work as a whole, and have given their approval for this version to be published.

Authorship Contributions. The co-authors of the article remained in control of its content throughout. Additionally, all co-authors contributed substantially to the conception, design, content and interpretation of data in the article, participated in its drafting and critical revision for intellectual content, approved the final version for submission, and acknowledge that they are accountable for all aspects of the article.

Disclosures. Karim Taha is an employee of Merck. Isa Ahmed AlSharoqi, Mohamed Aljumah, Saeed Bohlega, Abdelkader Daif, Salam ElKoussa, Jihad Inshasi, Murat Kurtuncu, Thomas 
Müller, Chris Retief, Vahid Shaygannejad, Ilham Slassi and Magd Zakaria have provided consultancy services to Merck. Cavit Boz received conference travel support from Biogen, Novartis, Bayer-Schering, Merck and Teva; has participated in clinical trials by Sanofi Aventis, Roche and Novartis. Per Soelberg Sørensen has received personal compensation for serving on scientific advisory boards, steering committees, independent data monitoring committees or has received speaker honoraria for Biogen, Merck, Novartis, TEVA, GlaxoSmithKline, MedDay Pharmaceuticals, Sanofi Aventis/Genzyme, Celgene and Forward Pharma. Mohammad Ali Sahraian received educational, research grants, lecture honorarium, travel supports to attend scientific meetings from Biogen-Idec, Merck-Serono, Bayer-Schering- Novartis, Cinnagen, Osveh, Zistdaru, Zahravi and Genzyme.

Compliance with Ethics Guidelines. This article is based on previously conducted studies and does not contain any studies with human participants or animals performed by any of the authors.

Data Sharing. Data sharing is not applicable to this article as no datasets were generated or analyzed during the current study.

Open Access. This article is licensed under a Creative Commons Attribution-NonCommercial 4.0 International License, which permits any non-commercial use, sharing, adaptation, distribution and reproduction in any medium or format, as long as you give appropriate credit to the original author(s) and the source, provide a link to the Creative Commons licence, and indicate if changes were made. The images or other third party material in this article are included in the article's Creative Commons licence, unless indicated otherwise in a credit line to the material. If material is not included in the article's Creative Commons licence and your intended use is not permitted by statutory regulation or exceeds the permitted use, you will need to obtain permission directly from the copyright holder. To view a copy of this licence, visit http://creativecommons.org/licenses/by$\mathrm{nc} / 4.0 /$.

\section{REFERENCES}

1. Shimizu Y, Ikeguchi R, Kitagawa K. When and how disease-modifying drugs for multiple sclerosis should be changed in daily practice. Clin Exp Immunol. 2017;8:71-80.

2. Zakaria M. Smoke and mirrors: Limited value of relative risk reductions for assessing the benefits of disease-modifying therapies for multiple sclerosis. Mult Scler Relat Disord. 2015;4:187-91.

3. Comi G, Radaelli M, Soelberg SP. Evolving concepts in the treatment of relapsing multiple sclerosis. Lancet. 2017;389:1347-56.

4. Burks JS. A practical approach to immunomodulatory therapy for multiple sclerosis. Phys Med Rehabil Clin N Am. 2005;16:449-66.

5. WHO Collaborating Centre for Drug Statistics Methodology. ATC/DDD index 2018. Available at https://www.whocc.no/atc_ddd_index. Accessed April 2020.

6. Francis G, Kappos L, O'Connor P, et a;. Temporal profile of lymphocyte counts and relationship with infections with fingolimod therapy. Mult Scler. 2014;20:471-80.

7. Linker RA, Gold R. Dimethyl fumarate for treatment of multiple sclerosis: mechanism of action, effectiveness, and side effects. Curr Neurol Neurosci Rep. 2013;13:394.

8. Stüve $\mathrm{O}$, Marra $\mathrm{CM}$, Jerome $\mathrm{KR}$, et al. Immune surveillance in multiple sclerosis patients treated with natalizumab. Ann Neurol. 2006;59:743-7.

9. Hauser SL, Bar-Or A, Comi G, et al. Ocrelizumab versus interferon beta-1a in relapsing multiple sclerosis. N Engl J Med. 2017;376:221-34.

10. Bar-Or A, Pachner A, Menguy-Vacheron F, Kaplan J, Wiendl $\mathrm{H}$. Teriflunomide and its mechanism of action in multiple sclerosis. Drugs. 2014;74:659-74.

11. Montes Diaz G, Fraussen J, Van Wijmeersch B, Hupperts R, Somers V. Dimethyl fumarate induces a persistent change in the composition of the innate and adaptive immune system in multiple sclerosis patients. Sci Rep. 2018;8:8194.

12. Celius EG. Infections in patients with multiple sclerosis: Implications for disease-modifying therapy. Acta Neurol Scand. 2017;136[Suppl 201]:34-6.

13. Epstein DJ, Dunn J, Deresinski S. Infectious complications of multiple sclerosis therapies: implications for screening, prophylaxis, and management. Open Forum Infect Dis. 2018;5:174. 
14. Lebrun C, Rocher F. Cancer risk in patients with multiple sclerosis: potential impact of diseasemodifying drugs. CNS Drugs. 2018;32:939-49.

15. Ragonese P, Aridon P, Vazzoler G, et al. Association between multiple sclerosis, cancer risk, and immunosuppressant treatment: a cohort study. BMC Neurol. 2017;17:155.

16. Burman J, Tolf A, Hägglund H, Askmark H. Autologous haematopoietic stem cell transplantation for neurological diseases. J Neurol Neurosurg Psychiatry. 2018;89:147-55.

17. Massey JC, Sutton IJ, Ma DDF, Moore JJ. Regenerating immunotolerance in multiple sclerosis with autologous hematopoietic stem cell transplant. Front Immunol. 2018;9:410.

18. Sellner J, Rommer PS. Immunological consequences of "immune reconstitution therapy" in multiple sclerosis: a systematic review. Autoimmun Rev. 2020;19:102492.

19. Sorensen PS, Sellebjerg F. Pulsed immune reconstitution therapy in multiple sclerosis. Ther Adv Neurol Disord. 2019;12:1756286419836913.

20. Giovannoni G. Immune reconstitution in MS: How does this impact treatment decisions? Medscape EDUCATION. https://img.medscapestatic.com/ images/892/112/892112_transcript.pdf. Accessed April 2020.

21. AlJumah M, Alkhawajah MM, Qureshi S, et al. Cladribine tablets and relapsing-remitting multiple sclerosis: a pragmatic, narrative review of what physicians need to know. Neurol Ther. 2020. https://doi.org/10.1007/s40120-020-00177-5.

22. Electronic Medicines Compendium. Lemtrada. European summary of product characteristics. https://www.medicines.org.uk/emc/product/5409. Accessed April 2020.

23. Havrdova E, Cohen JA, Horakova D, Kovarova I, Meluzinova E. Understanding the positive benefit: risk profile of alemtuzumab in relapsing multiple sclerosis: perspectives from the Alemtuzumab Clinical Development Program. Ther Clin Risk Manag. 2017;13:1423-37.

24. van der Zwan M, Baan CC, van Gelder T, Hesselink DA. Review of the clinical pharmacokinetics and pharmacodynamics of alemtuzumab and its use in kidney transplantation. Clin Pharmacokinet. 2018;57:191-207.

25. Gross CC, Ahmetspahic D, Ruck T, et al. Alemtuzumab treatment alters circulating innate immune cells in multiple sclerosis. Neurol Neuroimmunol Neuroinflamm. 2016;3:e289.
26. Thomas K, Eisele J, Rodriguez-Leal FA, Hainke U, Ziemssen T. Acute effects of alemtuzumab infusion in patients with active relapsing-remitting MS. Neurol Neuroimmunol Neuroinflamm. 2016;3: e228.

27. Baker D, Giovannoni G, Schmierer K. Marked neutropenia: Significant but rare in people with multiple sclerosis after alemtuzumab treatment. Mult Scler Relat Disord. 2017;18:181-3.

28. Coles AJ, Wing M, Smith S, et al. Pulsed monoclonal antibody treatment and autoimmune thyroid disease in multiple sclerosis. Lancet. 1999;354: 1691-5.

29. Comi G, Alroughani R, Boster AL, et al. Efficacy of alemtuzumab in relapsing-remitting MS patients who received additional courses after the initial two courses: Pooled analysis of the CARE-MS, extension, and TOPAZ studies. Mult Scler. 2019. https://doi. org/10.1177/1352458519888610.

30. Van Wijmeersch B, Singer BA, Boster A, et al. Efficacy of alemtuzumab over 6 years in relapsingremitting multiple sclerosis patients who relapsed between courses 1 and 2: Post hoc analysis of the CARE-MS studies. Mult Scler. 2019. https://doi.org/ $10.1177 / 1352458519881759$.

31. Buonomo AR, Zappulo E, Viceconte G, Scotto R, Borgia G, Gentile I. Risk of opportunistic infections in patients treated with alemtuzumab for multiple sclerosis. Expert Opin Drug Saf. 2018;17:709-17.

32. Guarnera C, Bramanti P, Mazzon E. Alemtuzumab: a review of efficacy and risks in the treatment of relapsing remitting multiple sclerosis. Ther Clin Risk Manag. 2017;13:871-9.

33. Nath A, Berger JR. Complications of immunosuppressive/immunomodulatory therapy in neurological diseases. Curr Treat Opt Neurol. 2012;14: 241-55.

34. Scappaticcio L, Castellana M, Virili C, et al. Alemtuzumab-induced thyroid events in multiple sclerosis: a systematic review and meta-analysis. J Endocrinol Invest. 2020;43:219-29.

35. Rotondi M, Molteni M, Leporati P, Capelli V, Marinò $\mathrm{M}$, Chiovato L. Autoimmune thyroid diseases in patients treated with alemtuzumab for multiple sclerosis: an example of selective anti-TSH-receptor immune response. Front Endocrinol (Lausanne). 2017;8:254.

36. Willis MD, Robertson NP. Alemtuzumab for multiple sclerosis. Curr Neurol Neurosci Rep. 2016;16:84.

37. US Food and Drug Administration. Lemtrada ${ }^{\circledR}$ US precribing information. https://www.accessdata. 
fda.gov/drugsatfda_docs/label/2014/

103948s5139lbl.pdf. Accessed April 2020.

38. Foley J, Carrillo-Infante C, Smith J, et al. The 5-year Tysabri Global Observational Program in Safety (TYGRIS) study confirms the long-term safety profile of natalizumab treatment in multiple sclerosis. Mult Scler Relat Disord. 2019. https://doi.org/10. 1016/j.msard.2019.101863

39. European Medicines Agency. Lemtrada. Measures to minimise risk of serious side effects of multiple sclerosis medicine. 2019. https://www.ema.europa. eu/en/medicines/human/referrals/lemtrada. Accessed April 2020.

40. U.S. Food and Drug Administration. FDA warns about rare but serious risks of stroke and blood vessel wall tears with multiple sclerosis drug Lemtrada (alemtuzumab). FDA Drug Safety Communication. 2018. https://www.fda.gov/drugs/drugsafety-and-availability/fda-warns-about-rareserious-risks-stroke-and-blood-vessel-wall-tearsmultiple-sclerosis-drug. Accessed April 2020.

41. Electronic Medicines Compendium. Mavenclad. European summary of product characteristics. https://www.medicines.org.uk/emc/product/8435. Accessed April 2020.

42. Soelberg-Sorensen P. Long-term lymphocyte counts in patients with relapsing-remitting multiple sclerosis (rrms) treated with cladribine Tablets $3.5 \mathrm{mg} /$ $\mathrm{kg}$ : total lymphocytes, $\mathrm{B}$ and $\mathrm{T}$ cell subsets. In: Program and abstracts of the annual meeting of the European Committee for Treatment and Research in Multiple Sclerosis, 2017, Abstract P665 (poster). https://onlinelibrary.ectrims-congress.eu/ectrims/ 2017/ACTRIMS-ECTRIMS2017/200310/per. soelberg-sorensen.long-term.lymphocyte.counts. in.patients.with.html. Accessed April 2020.

43. Guarnaccia JB, Rinder H, Smith B. Preferential depletion of lymphocyte subpopulations by cladribine in a phase III clinical trial in multiple sclerosis. In: Program and abstracts of the World Congress on Treatment and Research in Multiple Sclerosis, Montreal, September 17-20, 2008. Poster.

44. Leist TP, Weissert R. Cladribine: mode of action and implications for treatment of multiple sclerosis. Clin Neuropharmacol. 2011;34:28-35.

45. EMD Serono, Inc. Mavenclad ${ }^{\circledR}$ US prescribing information. https://www.emdserono.com/ MavencladPI. Accessed April 2020.

46. Giovannoni G, Comi G, Cook S, et al. CLARITY Study Group A placebo-controlled trial of oral cladribine for relapsing multiple sclerosis. N Engl J Med. 2010;362:416-26.
47. Cook S, Comi G, Rieckmann P, et al. Safety and tolerability of cladribine tablets in patients with relapsing-remitting multiple sclerosis (RRMS): final results from the 120 -week phase $3 \mathrm{~b}$ extension trial to the CLARITY study. Poster presented at 68th American Academy of Neurology Annual Meeting, 15-21 April 2016; Vancouver. Poster P3.095.

48. Comi G, Cook SD, Giovannoni G, et al. MRI outcomes with cladribine tablets for multiple sclerosis in the CLARITY study. J Neurol. 2013;260:1136-46.

49. Giovannoni G, Soelberg Sorensen P, Cook S, et al. Safety and efficacy of cladribine tablets in patients with relapsing-remitting multiple sclerosis: results from the randomized extension trial of the CLARITY study. Mult Scler. 2018;724(12): 1594-1604.

50. Comi G, Cook S, Rammohan K, et al. Long-term effects of cladribine tablets on MRI activity outcomes in patients with relapsing-remitting multiple sclerosis: the CLARITY Extension study. Ther Adv Neurol Disord. 2018;11:1756285617753365.

51. Leist TP, Comi G, Cree BA, et al. Effect of oral cladribine on time to conversion to clinically definite multiple sclerosis in patients with a first demyelinating event (ORACLE MS): a phase 3 randomised trial. Lancet Neurol. 2014;13:257-67.

52. Aruta F, Iovino A, Costa C, Manganelli F, Iodice R. Lichenoid rash: a new side effect of oral Cladribine. Mult Scler Relat Disord. 2020;41:102023.

53. Pakpoor J, Disanto G, Altmann DR, et al. No evidence for higher risk of cancer in patients with multiple sclerosis taking cladribine. Neurol Neuroimmunol Neuroinflamm. 2015;2:e158.

54. European Medicines Agency. Assessment report. MAVENCLAD. International non-proprietary name: cladribine. Procedure No. EMEA/H/C/ 004230/0000. 2017. https://www.ema.europa.eu/ docs/en_GB/document_library/EPAR_-_Public assessment_report/human/004230/WC500234563. pdf. Accessed April 2020.

55. Cook S, Leist T, Comi G et al. Safety of cladribine tablets in the treatment of patients with multiple sclerosis: An integrated analysis. Mult Scler Relat Disord. 2019; 29:157-67.

56. Frau J, Coghe G, Lorefice L, Fenu G, Cocco E. New horizons for multiple sclerosis therapeutics: milestones in the development of ocrelizumab. Neuropsychiatr Dis Treat. 2018;14:1093-9.

57. Electronic Medicines Compendium. Ocrevus. European summary of product characteristics. 2019. https://www.medicines.org.uk/emc/product/ 8898. Accessed April 2020. 
58. Steinberg SC, Faris RJ, Chang CF, Chan A, Tankersley MA. Impact of adherence to interferons in the treatment of multiple sclerosis: a non-experimental, retrospective, cohort study. Clin Drug Investig. 2010;30:89-100.

59. Giovannoni G, Turner B, Gnanapavan S, Offiah C, Schmierer K, Marta M. Is it time to target no evident disease activity (NEDA) in multiple sclerosis? Mult Scler Relat Disord. 2015;4:329-33.

60. Wong B, Cahill J, Rizvi S. Moving towards a cure for MS: Increased immunosuppression and striving for no evidence of disease activity (NEDA). R I Med J. 2013;2018(101):26-9.

61. Giovannoni G, Tomic D, Bright JR, Havrdová E. “No evident disease activity": the use of combined assessments in the management of patients with multiple sclerosis. Mult Scler. 2017;23:1179-87.

62. Giovannoni G, Cook S, Rammohan K, et al. Sustained disease-activity-free status in patients with relapsing-remitting multiple sclerosis treated with cladribine tablets in the CLARITY study: a post-hoc and subgroup analysis. Lancet Neurol. 2011;10: 329-37.

63. Traboulsee A, Arnold D, Bar-Or A, et al. Ocrelizumab No Evidence of Disease Activity (NEDA) status at 96 weeks in patients with relapsing multiple sclerosis: analysis of the phase III doubleblind, double-dummy, interferon beta-1a-controlled OPERA I and OPERA II studies (PL02.004). Neurology. 2016; 86[Suppl 1]:PL02:004 (abstract). https://n.neurology.org/content/86/16 Supplement/PL02.004. Accessed April 2020.

64. Cohen JA, Coles AJ, Arnold DL, et al. Alemtuzumab versus interferon beta $1 \mathrm{a}$ as first-line treatment for patients with relapsing-remitting multiple sclerosis: a randomised controlled phase 3 trial. Lancet. 2012;380:1819-28.

65. Coles AJ, Twyman CL, Arnold DL, et al. Alemtuzumab for patients with relapsing multiple sclerosis after disease-modifying therapy: a randomised controlled phase 3 trial. Lancet. 2012;380:1829-39.
66. Polman $\mathrm{CH}, \mathrm{O}^{\prime}$ Connor PW, Havrdova E, et al. A randomized, placebo-controlled trial of natalizumab for relapsing multiple sclerosis. N Engl J Med. 2006;354:899-910.

67. Havrdova E, Galetta S, Hutchinson M, et al. Effect of natalizumab on clinical and radiological disease activity in multiple sclerosis: a retrospective analysis of the Natalizumab safety and efficacy in relapsing-remitting multiple sclerosis (AFFIRM) study. Lancet Neurol. 2009;8:254-60.

68. Kappos L, Radue EW, O'Connor P, et al. A placebocontrolled trial of oral fingolimod in relapsing multiple sclerosis. N Engl J Med. 2010;362:387-401.

69. Bevan CJ, Cree BA. Disease activity free status: a new end point for a new era in multiple sclerosis clinical research? JAMA Neurol. 2014;71:269-70.

70. Gold R, Kappos L, Arnold DL, et al. Placebo-controlled phase 3 study of oral BG-12 for relapsing multiple sclerosis. N Engl J Med. 2012;367: 1098-107.

71. Giovannoni G, Gold R, Kappos L et al. BG-12 increases the proportion of patients free of clinical and radiologic disease activity in relapsing-remitting multiple sclerosis: findings from the DEFINE study (PD5.005). Neurology 2012;78 [Suppl 1]:PD5. 934 (abstract). https://n.neurology.org/content/78/ 1_Supplement/PD5.005. Accessed April 2020.

72. O'Connor P, Wolinsky JS, Confavreux C, et al. Randomized trial of oral teriflunomide for relapsing multiple sclerosis. N Engl J Med. 2011;365: 1293-303.

73. Freedman $\mathrm{M}, \mathrm{O}^{\prime}$ Connor $\mathrm{P}$, Wolinsky, $\mathrm{J}$ et al. Teriflunomide increases the proportion of patients free from disease activity in the TEMSO Phase III Study (PD5.007). Neurology. 2012;78[Suppl 1]:PD5.007 (abstract). https://n.neurology.org/content/78/1_ Supplement/PD5.007. Accessed April 2020.

74. Vermersch P, Martinelli V, Pfleger C, et al. Benefit-risk assessment of cladribine using multi-criteria decision analysis (MCDA) for patients with relapsing-remitting multiple sclerosis. Clin Ther. 2019;41: 249-260. 